\title{
Isolation of a Microorganic Strain for the High Volume Degradation of Aniline Blue and Its Application in Natural Sewage Treatment
}

\author{
Wenhao Li ${ }^{*}$, Cheng $\mathrm{Li}^{1 *}$, Yuxiang Xu${ }^{1}$, Qin Wang1, Xin Ma1, Shouwen Chen ${ }^{1}$, Jun Yu${ }^{2 \#, ~ Y o n g ~ Y a n g 1 \# ~}$ \\ ${ }^{1}$ Hubei Collaborative Innovation Center for Green Transformation of Bio-Resources, Hubei University, Wuhan, China \\ ${ }^{2}$ Tobacco Research Institute of Hubei Province, Wuhan, China \\ Email: "80196867@ qq.com, "519971800@qq.com
}

How to cite this paper: Li, W.H., Li, C., Xu, Y.X., Wang, Q., Ma, X., Chen, S.W., $\mathrm{Yu}, \mathrm{J}$. and Yang, Y. (2018) Isolation of a Microorganic Strain for the High Volume Degradation of Aniline Blue and Its Application in Natural Sewage Treatment. Computational Molecular Bioscience, 8, 149-165. https://doi.org/10.4236/cmb.2018.84008

Received: November 9, 2018

Accepted: December 14, 2018

Published: December 17, 2018

Copyright $\odot 2018$ by authors and Scientific Research Publishing Inc. This work is licensed under the Creative Commons Attribution International License (CC BY 4.0).

http://creativecommons.org/licenses/by/4.0/ (c) $\underset{\mathrm{EY}}{\mathrm{EY}}$ Open Access

\begin{abstract}
Aniline blue, one of the triphenylmethane dyes, is the most commonly produced and used of these dyes yet it is also the most dangerous and the most serious cause of pollution amongst them. An exploration of aniline blue degradation is likely to facilitate an understanding of the degradation mechanism for a range of related dyes. In this study, we managed to isolate a particular strain of microorganism, identified to be Lysinibacillus fusiformis N019a, which showed a significant capacity for aniline blue degradation in both laboratory tests and natural sewage treatment. In analysis aided by a UV-Visible spectrophotometer, we found that $96.7 \%$ of aniline blue had degraded within 24 hours under laboratory conditions. When treating natural sewage, $80.1 \%$ of the aniline blue was removed after just 16 hours. Further analysis has shown that Lysinibacillus fusiformis $\mathrm{N} 019$ a has a strong resistance to $\mathrm{Cu}^{2+}, \mathrm{Mn}^{2+}, \mathrm{Zn}^{2+}$, and $\mathrm{Pb}^{2+}$. We also found that the degradation product of aniline blue by Lysinibacillus fusiformis $\mathrm{N} 019 \mathrm{a}$ was of reduced toxicity to plants and microbes.
\end{abstract}

\section{Keywords}

Aniline Blue, Dye Degradation, Lysinibacillus fusiformis N019a, Natural Sewage Treatment

\section{Introduction}

More than 0.7 million tons of triphenylmethane dyes are used annually in textile production and other related industries [1] [2]. However, synthetic dyes are no-

*These authors contributed equally to this work.

"Correspondence should be addressed to: Yujun (80196867@qq.com) and Yang Yong (519971800@qq.com). 
toriously difficult to degrade [3], so approximately $15 \%$ of synthetic dyes end up being released into the environment [4] [5] [6], with potentially harmful health and ecological outcomes [7]. In aqueous ecosystems, synthetic dyes can inhibit photosynthesis and in terrestrial ecosystems [8] [9], the primary broken-down molecules of synthetic dyes are known to have a detrimental effect on microorganisms [10], animals and grain crops [11] [12]. For human-beings, some synthetic dyes are potentially carcinogenic and mutagenic and can be harmful to the immune and respiratory systems [1] [2] [8] [13] [14].

In view of these health and ecological concerns [7] [15], chemical, physical and biological methods have been recruited to treat triphenylmethane dyes being harbored in the environment [2] [16]. Chemical and physical approaches, however, have proved relatively ineffective and expensive and a number of researchers have pointed to the significant secondary contamination produced by these treatments [6] [7] [17] [18].

Biological treatments are considered more environmentally friendly, less costly and more likely to succeed than physicochemical methods [4] [8] [12]. Microbial degradation of triphenylmethane dyes, in particular, has received a lot of attention [7] [19] [20]. The distinguishing features of this approach are lower treatment costs and higher efficiency [21]. This is because microorganisms are able to use triphenylmethane dyes as nutrients without the need for additional supplements [6] [22]. Fungi are considered to be the primary representative species capable of removing triphenylmethane dyes [23] [24] [25]. Amongst them, Phanerochaete chrysosporium [26], Irpex lacteus [27], Pleurotus ostreatus [27], Aspergillus fusiformis [28], Penicillium fusiformis and Fusarium have all been reported to successfully degrade triphenylmethane dyes [29] [30].

However, fungi are not well-adapted to aqueous ecosystems and this has limited the comprehensive and practical biological treatment of triphenylmethane dyes. Confronted with this problem, bacterium would seem to offer the optimum alternative [12] [16] [31]. To date, Pseudomonas, Bacillus, Sphingomonas, Aeromonas, Citrobacter, Escherichia, Desulphovibrio, Proteus, Schewanella and Alcaligenes have had success in removing triphenylmethane dyes [4] [6].

Usually, microbiological removal of triphenylmethane dyes is primarily dependent on three kinds of essential enzymes. These are: laccase (Lac), ligninperoxidase (LiP), and manganeseperoxidase ( $\mathrm{MnP}$ ) [32] [33] [34]. In previous work, some authors have reported the pre-screening of pure single microorganisms for high-level enzyme activity so as to construct specific consortia for the removal of triphenylmethane dyes [35] [36]. Other authors have suggested that a microbial mixture will result in the simultaneous secretion of several kinds of enzymes, leading to a more complete removal of the dyes [2]. Others again have argued that prior high-level expression of the required enzymes is the most efficient way of breaking down the molecular structure of triphenylmethane dyes [37] [38] [39]. However, the role of enzyme activity in triphenylmethane dye degradation is not the absolute determinant. The efficiency of triphenylmethane dye removal results from having a balance of organism type, the specific condi- 
tions of use and the character of the dyes themselves [4] [22].

In general, most investigators tend to pay more attention to representative triphenylmethane dyes, such as Crystal Violet (CV), Methyl Violet (MV), Malachite Green (MG) and Cotton Blue (CB). However, another important triphenylmethane dye, aniline blue, is largely overlooked. Yet, in fact, aniline blue is more widely used than the other members of the triphenylmethane dye family. It is used not only in the polymer, rubber, agricultural and dye industries [40], but also as a staining marker in molecular research [41]. At the same time, the presence of three sulfonic acid groups in aniline blue give it high polarity, making it very difficult to degrade with ordinary microbes [42]. So, aniline blue is capable of producing particularly dangerous and serious pollution [43]. In view of its greater resistance, exploration of aniline blue degradation may further facilitate understanding of the degradation mechanism for other triphenylmethane dyes, Research, here, may also be more broadly beneficial for the development of degradation microbes for bioremediation.

The core background to the work presented here is the exploration of how to approach the degradation of aniline blue with newly-screened microorganisms that have the capacity to bring about highly efficient removal of triphenylmethane dyes. There are thousands of millions of microorganisms in the environment and many of them are likely to offer effective possibilities for triphenylmethane dye removal.

\section{Materials and Methods}

\subsection{Isolation and Identification of Microbes for Degradation of Aniline Blue}

A wild-type strain of Lysinibacillus fusiformis N019a was isolated from decomposed timber in a wood-working factory in Enshi, Hubei province, China. The actual process of isolating this microbe has been previously described in [7] and [12]. The DNA sequence of the 16S RNA region of the microbe was blasted in NCBI and exported similar sequences used neighbor-joining method to construct phylogenetic tree by MEGA7.0. Throughout the duration of our experiments, strains were cultured in a Luria-Bertani (LB) medium at $37^{\circ} \mathrm{C}$.

The medium used for testing degradation of aniline blue (DAB) contained (g. $\mathrm{L}^{-1}$ ): Lactate 1.62, $\mathrm{NaOH} 0.3, \mathrm{NH}_{4} \mathrm{Cl} 1.5, \mathrm{KCl} 0.1, \mathrm{NaH}_{2} \mathrm{PO}_{4} 0.516, \mathrm{NaCl} 5.85$, yeast extract 0.5 and a trace mineral stock solution, The medium also contained $50 \mathrm{mg} / \mathrm{L}$ aniline blue (Sinopharm Chemical Reagent Co., Ltd.) and was adjusted to $\mathrm{pH} 7.0$ unless otherwise mentioned. All of the Erlenmeyer flasks containing $50 \mathrm{ml}$ of the $\mathrm{DAB}$ medium were autoclaved at $121^{\circ} \mathrm{C}$ for $20 \mathrm{~min} .4 \% \log$ phase cells of Lysinibacillus fusiformis N019a were inoculated into each flask. Each experimental sample was incubated in a thermostat oscillator at $37^{\circ} \mathrm{C}$ at $120 \mathrm{rpm}$ for 36 hours. The cultured cells were harvested via centrifuge $(12,000 \times \mathrm{g} ; 10$ min) using a Beckman Coulter Microfuge 20 under $4^{\circ} \mathrm{C}$. Degradation was determined in relation to a cell-free supernatant. The uninoculated sterile dye-containing 
medium was used as control. The degradation ratio was calculated using the following equation:

$$
\text { Degradation } \%=\left[\frac{A_{2}-A_{1}}{A_{2}}\right] \times 100 \%
$$

$A_{1}=$ Final absorbance of dye after microbe incubation; $A_{2}=$ Initial absorbance (Control check). Absorbance was detected using a UV-Visible spectrophotometer at $585 \mathrm{~nm}$ (INESA $752 \mathrm{~N}$, China).

\subsection{Dye Degradation Rate According to Different Parameters}

The degradation rate of dyes can be influenced by the initial dye concentration, the $\mathrm{pH}$ of the treatment medium and the incubation temperature [7]. In this study, we chose single factor experiment, the initial dye concentrations tests were set at 50,100, 200, 500 and $1000 \mathrm{mg} \cdot \mathrm{L}^{-1}$, using electronic micro balance (METTLER TOLEDO), the $\mathrm{pH}$ tests were containing in $5.5-8.0$, adjusted by $\mathrm{pH}$ meter (METTLER TOLEDO), and the temperature tests were ranged from $15^{\circ} \mathrm{C}$ to $45^{\circ} \mathrm{C}$ with the blanking of $5^{\circ} \mathrm{C}$, cultured in incubator shaker (Honour). As indicated above, excepted the variable of each group, the initial dye concentration, $\mathrm{pH}$ and temperature was kept at $50 \mathrm{mg} \cdot \mathrm{L}^{-1}, 7.0$ and $37^{\circ} \mathrm{C}$ respectively, and all the shake speed were at $120 \mathrm{rpm}$.

To explore the influence of carbon and nitrogen sources on aniline blue degradation, $0.5 \%$ of sucrose, glucose, mannitol, maltose, starch, peptone, yeast extract (YE), sodium carbonate, sodium lactate (SL) and SL + YE were loaded as carbon sources. Inorganic nitrogen $\left(0.2 \%\right.$ of $\left(\mathrm{NH}_{3}\right)_{2} \mathrm{SO}_{4}$, Urea, $\mathrm{CH}_{3} \mathrm{COONH}_{4}$, $\mathrm{NH}_{4} \mathrm{NO}_{3}$ and $\mathrm{NaNO}_{3}$ ), organic nitrogen ( $0.2 \%$ of peptone, yeast extract) and sodium lactate $(0.5 \%)$ were chosen as nitrogen sources. To examine the impact of salinity on degradation efficiency, a graded concentration of $\mathrm{NaCl}(0,5,10,20$, 40,60 , and $80 \mathrm{~g} / \mathrm{L}$ ) was added into the medium. We also considered it important to investigate the effects of several heavy metallic ions commonly found in dyeing wastewater on Lysinibacillus fusiformis N019a. The toxicity of heavy metals to microbes can be calculated using the following exponential function:

$$
y=a \mathrm{e}^{-b x}
$$

$x=$ The metallic ion concentration $/ \mathrm{mmol} \cdot \mathrm{L}^{-1} ; y=$ The biomass in the medium containing the metallic ions $/ \mathrm{mmol} \cdot \mathrm{L}^{-1} ; a=$ The biomass in the medium containing no metallic ion; $b=$ The toxicity index. The $b$ value is positively related to the toxicity.

\subsection{Degradation Assay in Natural Sewage}

As another part of this study, natural wastewater was collected from the Wuhan Printing and Dyeing Factory. The primary concentration of aniline blue was detected by spectrophotometry $(585 \mathrm{~nm})$ and $4 \mathrm{ml}$ of Lysinibacillus fusiformis $\mathrm{N} 019 \mathrm{a}\left(1.5 \times 10^{8} \mathrm{CFU} / \mathrm{mL}\right)$ was inoculated in $100 \mathrm{ml}$ natural sewage. The degradation ratio was detected by spectrophotometry $(585 \mathrm{~nm})$ every $4 \mathrm{~h}$. 


\subsection{Phytotoxicity and Microbial Toxicity Assay}

In order to assess the phytotoxicity and microbial toxicity of aniline blue and its degradation/degradation products, the length of plumule and germination of tobacco, corn and tomato was measured. $10 \mathrm{~mL}$ of aniline blue $(50 \mathrm{mg} / \mathrm{L})$ and fermentation supernatant $(500 \mathrm{mg} / \mathrm{L}$ initial concentration and $24 \mathrm{~h}$ fermentation) were used to culture tobacco, corn and tomato with methylsulfonylmethane (MSM) as a control [44]. The toxicity to Bacillus amyloliquefaciens ZM9 was tested [45], with the mean inhibition zone (diameter in $\mathrm{cm}$ ) treated by MSM, aniline blue and fermentation supernatant being recorded after $24 \mathrm{~h}$ of incubation at $30^{\circ} \mathrm{C}$ on an LB plate [44] [46].

\subsection{Statistical Analysis}

All of the experiments were performed independently in triplicate and the differences amongst the treatments were subjected to a one-way analysis of variance (ANOVA) using a Tukey Kramer multiple comparisons test.

\section{Results and Discussion}

\subsection{Isolation and Identification of Microbes for Aniline Blue Degradation}

As mentioned above, the wild-type strain Lysinibacillus fusiformis N019a was originally isolated from decomposed timber in a wood-working factory in China [7] [12]. The DNA sequence of the 16S RNA region of the microbe was blasted in NCBI and the resulting phylogenetic tree revealed that it was close to Lysinibacillus fusiformis strain NFS-STR-1 (MF079349.1), Lysinibacillus sp. B4 (KC310820.1) and Lysinibacillus fusiformis strain HBUM07011 (MF662437.1) (Figure 1). The microbe was therefore inferred to be Lysinibacillus fusiformis N019a and deposited in GenBank (accession number BankIt2112285 N019a MH327493).

Aniline blue can be decolored within $3 \mathrm{~h}$ when the strain is mature. When $L y$ sinibacillus fusiformis N019a was cultured on the LB medium, an obvious transparent ring could be observed $8 \mathrm{~h}$ later. After a further $6 \mathrm{~h}$, the aniline blue had been completely decolored (see Figure 2(a)). The degradation rate of aniline

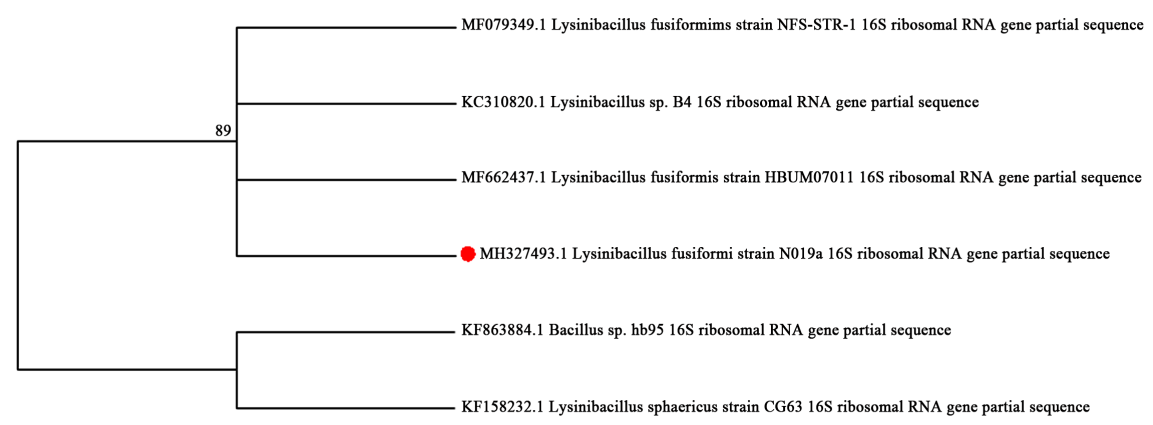

Figure 1. Distance tree inferred from the alignment of N019a after an NCBI BLAST search (MEGA7). 


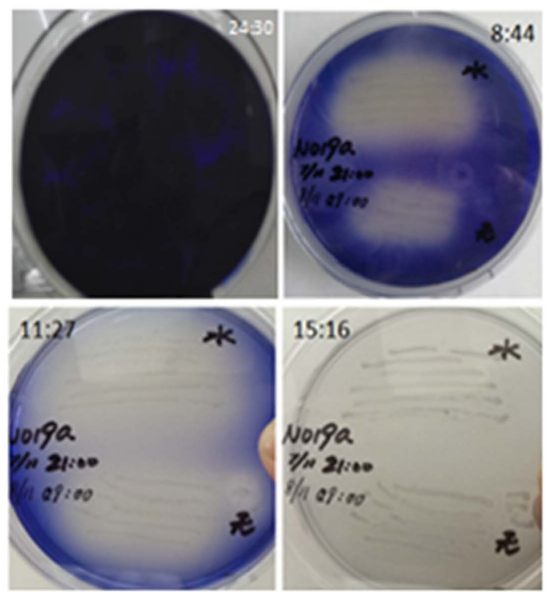

(a)

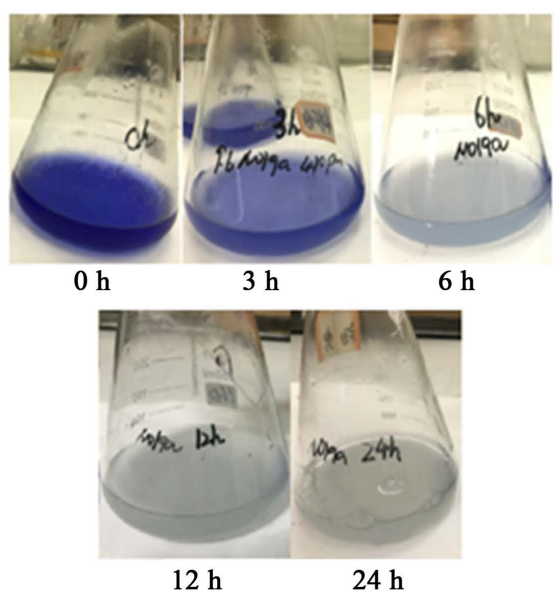

(b)

Figure 2. Schedule of aniline blue degradation induced by Lysinibacillus fusiformis N019a (a); Dynamic medium color change process after Lysinibacillus fusiformis N019 was inoculated (b).

blue initiated by Lysinibacillus fusiformis N019a was found to be higher than that reported for a number of other microbes in the literature [12] [39] [47].

About $3 \mathrm{~h}$ after inoculation of Lysinibacillus fusiformis N019 in a shake flask culture, the color of the aniline blue had started to discolor. $6 \mathrm{~h}$ later it was almost colorless (see Figure 2(b)) and after $24 \mathrm{~h}$ the fermentation culture had remained colorless. Comparing the degradation performance of Lysinibacillus fusiformis N019 for aniline blue against that of other microbes, it achieved degradation in a shorter period of time than Shewanella oneidensis MR-1 [12], Streptomyces AG-56 [39], Mucoromycotina fusiformis HS-3 [48], Bjerkandera fumosa X X-3 and Cerrena fusiformis A-02 [47] [49].

UV-visible absorption spectra were used to analyze the degradation of aniline blue by Lysinibacillus fusiformis N019a. The absorption spectrum of aniline blue and its degradation products was measured across wavelengths ranging from 350 to $640 \mathrm{~nm}$. Aniline blue solution has a characteristic absorption peak at 585 $\mathrm{nm}$, but this absorption peak disappeared when it was treated with Lysinibacillus fusiformis N019a (Figure 3(a)). In previous investigations, disappearance of an absorption peak has indicated that the chemical structure of the triphenylmethane dye has changed [25] [50]. These results therefore suggested that the aniline blue had been degraded by Lysinibacillus fusiformis N019a.

The absorption spectrum of aniline blue was explored across the $24 \mathrm{~h}$ fermentation period. After just the initial $3 \mathrm{~h}, 80 \%$ of the aniline blue had been degraded and at $6 \mathrm{~h}$ this had risen to $85 \%$. After $24 \mathrm{~h} 96.7 \%$ of the aniline blue had been degraded (see Figure 3(b)). All of this data indicates that the efficiency of aniline blue degradation induced by Lysinibacillus fusiformis N019a is higher than other microbes tested in the literature, such as $S$. oneidensis MR-1 (85.56\% after 96 h) Bjerkandera fumosa (90\% after 5 days) [12] [47], and Mucoromycotina fusiformis HS-3 (95\% after more than 5 days) [48]. 


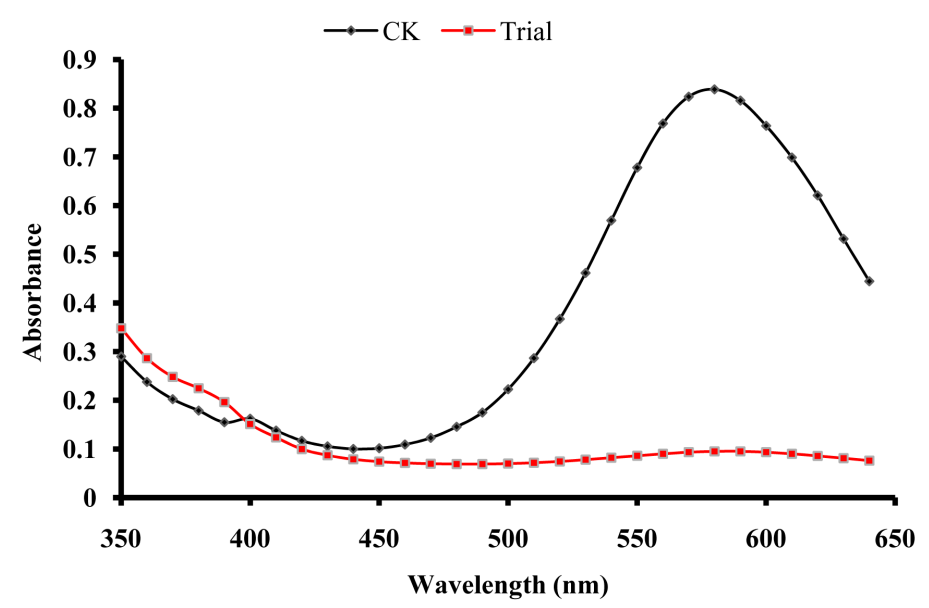

(a)

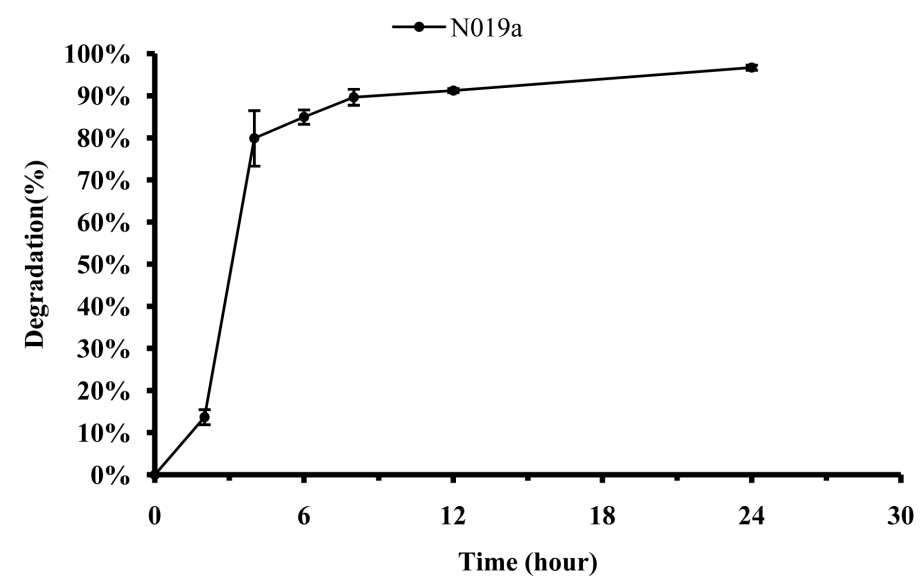

(b)

Figure 3. Degradation assays using UV-V is spectral analysis (a) and absorption spectra (b). (a) UV-V is spectral analysis of aniline blue (black curve) and its degradation products after incubation for $24 \mathrm{~h}$ with lysinibacillus sp. N019a (red curve); (b) Degradation (\%) of aniline blue by lysinibacillus sp. N019a over $24 \mathrm{~h}$.

\subsection{Dye Degradation Rate across Different Parameters}

The degradation rate of dyes can be influenced by the initial dye concentration [50]. This phenomenon was also found to hold in this investigation. Aniline blue can be more rapidly decolored at lower concentrations than higher ones during the initial $6 \mathrm{~h}$ (see Figure 4(a)). After 6 h, 86.5\% of aniline blue at a concentration of $50 \mathrm{mgL}^{-1}$ had been decolored. At $1000 \mathrm{mg} \cdot \mathrm{L}^{-1}$, this figure had dropped to only $63.5 \%$. However, after $12 \mathrm{~h}, 95.5 \%, 94.4 \%, 92.4 \%, 89.8 \%$ and $87.4 \%$ of the aniline blue had been decolored by Lysinibacillus fusiformis N019a at 50, 100, 200, 500 and $1000 \mathrm{mg} \cdot \mathrm{L}^{-1}$, respectively. The overall tendency for degradation efficiency at different concentrations is for it to gradually decrease as the aniline blue concentration increases. In line with several previous investigations [7] [51], we find the implication of this to be that the initial concentration of triphenylmethane dyes and microbial degradation efficiency is negatively correlated [39]. 


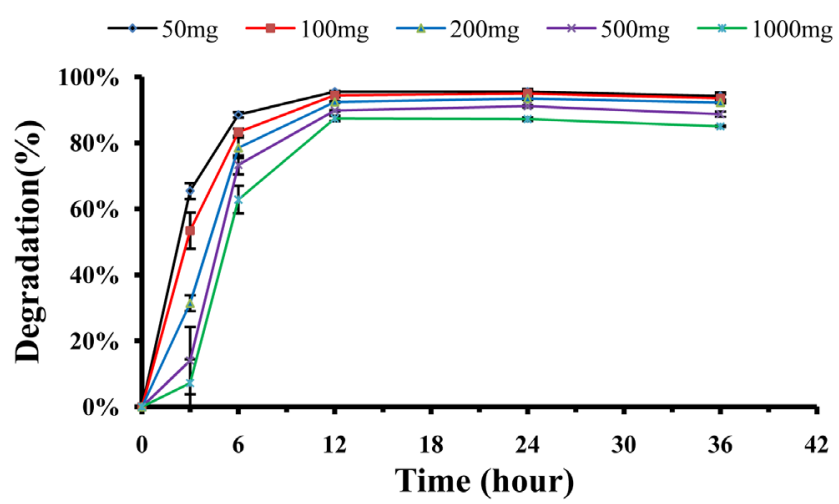

(a)

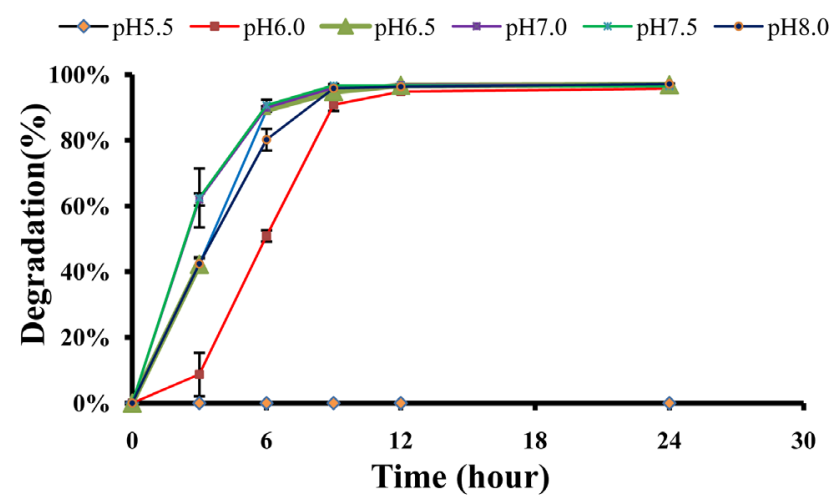

(b)

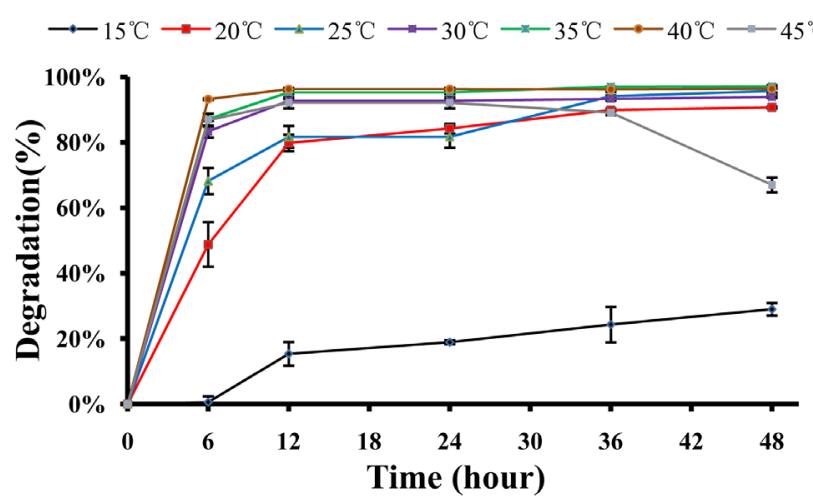

(c)

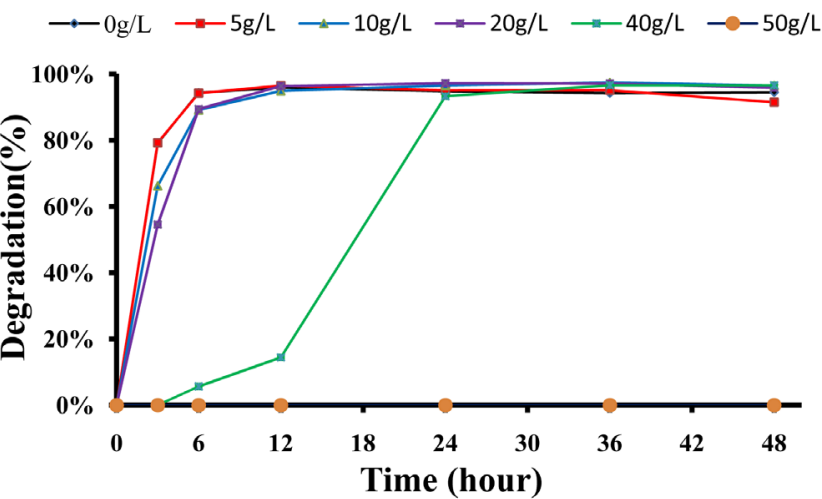

(d) 


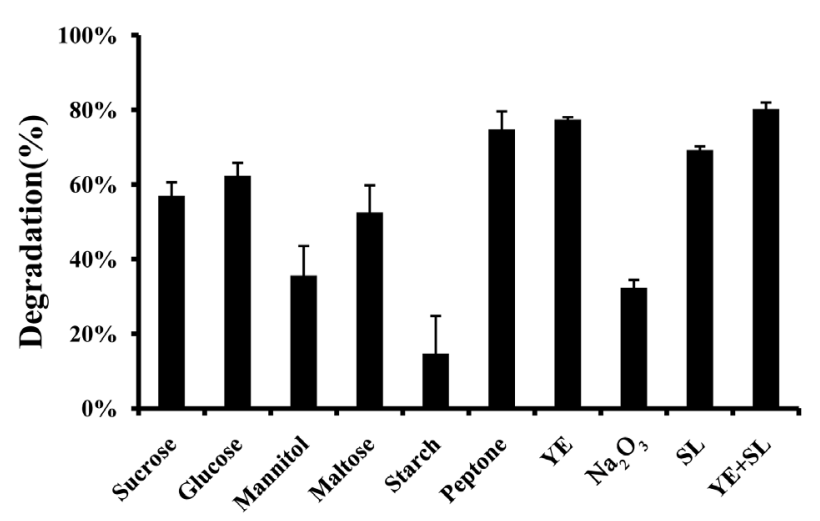

(e)

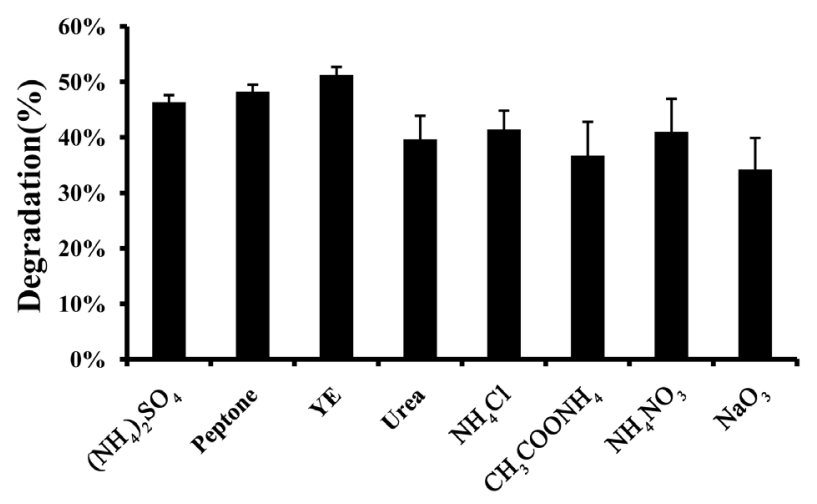

(f)

Figure 4. Effects on the degradation efficiency of lysinibacillus $s p$. N019a for: different initial concentrations of aniline blue (a); $\mathrm{pH}$ values (b); temperatures (c); salinity (d); carbon sources (e); and nitrogen sources. All values represent the average of the results across three samples \pm SD (standard deviation).

An optimum $\mathrm{pH}$ and temperature of the treatment medium is required to maximize the efficiency of dye degradation (Mishra and Maiti, 2018). Lysinibacillus fusiformis $\mathrm{N} 019$ a possessed a degradation capacity at $\mathrm{pH}$ 6.0 8.0. Its maximum degradation efficiency (97.1\%) was obtained at $\mathrm{pH} 8.0$ after incubation for $24 \mathrm{~h}$ (see Figure 4(b)). The degradation activity of Lysinibacillus fusiformis N019a was significantly influenced by temperature and was positively correlated with temperatures from $15^{\circ} \mathrm{C}$ to $40^{\circ} \mathrm{C}$. However, when the temperature was higher than $45^{\circ} \mathrm{C}$, the degradation efficiency started to decline (Figure $4(\mathrm{c})$ ). And the salinity tolerance of Lysinibacillus fusiformis N019a was higher than $40 \mathrm{~g} / \mathrm{L}$, although it dragged the growth of strain N019a at the front $12 \mathrm{~h}$ after inoculation, but it recovered after that, what can be seen clearly from Figure 4 (d).

As mentioned in Section 2.2, a DAB medium to which we had added $0.5 \%$ sucrose, glucose, mannitol, maltose, starch, peptone, yeast extract (YE), sodium carbonate, sodium lactate (SL) and SL + YE was used to explore the influence of carbon sources on aniline blue degradation. The degradation rate of aniline blue induced by Lysinibacillus fusiformis N019a using yeast extract, peptone and so- 
dium lactate as the unique carbon source reached $77.3 \%, 74.8 \%$ and $69.1 \%$, respectively (see Figure 4(e)), while using a composite carbon source of sodium lactate + yeast extract (4:1) enabled the degradation rate to reach $80.2 \%$. After comprehensive testing, sodium lactate + yeast extract (4:1) appears to be the optimal carbon source for Lysinibacillus fusiformis N019a. In addition, when inorganic nitrogen $(0.2 \%)$, organic nitrogen $(0.2 \%)$ and sodium lactate $(0.5 \%)$ were selected as the nitrogen source, $\left(\mathrm{NH}_{4}\right)_{2} \mathrm{SO}_{4}$ and yeast extract produced the best degradation results (Figure 4(f)).

It was noticed that Lysinibacillus fusiformis N019a was capable of maintaining a high degradation efficiency of over $94 \%$ for aniline blue after $36 \mathrm{~h}$ of incubation when the added $\mathrm{NaCl}$ concentration did not exceed $40 \mathrm{~g} \cdot \mathrm{L}^{-1}$. However, $L y$ sinibacillus fusiformis N019a spent longer adapting to growth at above $40 \mathrm{~g} \cdot \mathrm{L}^{-1}$ $\mathrm{NaCl}$. Color reduction disappeared once the saline concentration reached 60 $\mathrm{g} \cdot \mathrm{L}^{-1}$. As this figure is relatively high, it indicates that Lysinibacillus fusiformis N019a is able to tolerate a wide range of salt concentrations. This adaptability will clearly increase the feasibility of its practical application.

Some metal compounds in the environment do not have an adverse effect on microbes but, rather, are beneficial to them. However, when some metals, especially heavy metals, exceed a certain concentration, they have a toxic effect on microorganisms, inhibiting their growth and reproduction, damaging their respiration, making their cell morphology abnormal and even causing cell lysis. In that case, it was important to investigate the effects of several heavy metallic ions commonly found in dyeing wastewater on Lysinibacillus fusiformis N019a. Ag$\mathrm{SO}_{4}, \mathrm{CdCl}_{2}, \mathrm{~K}_{2} \mathrm{Cr}_{2} \mathrm{O}_{4}$ and $\mathrm{HgCl}_{2}$ had a significant toxic inhibition effect on the growth of Lysinibacillus fusiformis $\mathrm{N} 019 \mathrm{a}$, with a toxicity index ranging from 17.345 to 71.405 (see Table 1). The toxicity index of $\mathrm{CuSO}_{4}, \mathrm{MnSO}_{4}, \mathrm{ZnSO}_{4}$, $\mathrm{Pb}(\mathrm{Ac})_{2}$ was less, ranging from 0.094 to 2.591 . This shows that Lysinibacillus fusiformis $\mathrm{N} 019 \mathrm{a}$ has a strong resistance to $\mathrm{Cu}^{2+}, \mathrm{Mn}^{2+}, \mathrm{Zn}^{2+}, \mathrm{Pb}^{2+}$.

Table 1. Effect of heavy metallic ions on lysinibacillus sp. N019a.

\begin{tabular}{ccccc}
\hline $\begin{array}{c}\text { Metallic } \\
\text { ion }\end{array}$ & $\begin{array}{c}\text { Biomass } \\
(\mathrm{OD} 600)\end{array}$ & $\begin{array}{c}\text { Metallic ion concentration } \\
(\mathrm{mmol} / \mathrm{L})\end{array}$ & $\begin{array}{c}\text { Degradation } \\
(\%)\end{array}$ & $\begin{array}{c}\text { Toxicity } \\
\text { Index }\end{array}$ \\
\hline $\mathrm{CK}$ & 1.525 & - & $91.4 \%$ & - \\
$\mathrm{CuSO}_{4}$ & 0.115 & 1.00 & $6.2 \%$ & 2.588 \\
$\mathrm{AgSO}_{4}$ & 0.088 & 0.04 & $3.7 \%$ & 71.405 \\
$\mathrm{MnSO}_{4}$ & 0.151 & 1.00 & $13.5 \%$ & 2.312 \\
$\mathrm{CdCl}_{2}$ & 0.236 & 0.04 & $23.3 \%$ & 46.648 \\
$\mathrm{~K}_{2} \mathrm{Cr}_{2} \mathrm{O}_{4}$ & 0.762 & 0.04 & $87.8 \%$ & 17.345 \\
$\mathrm{ZnSO}_{4}$ & 0.114 & 1.00 & $10.3 \%$ & 2.591 \\
$\mathrm{~Pb}$ & 1.389 & 1.00 & $93.9 \%$ & 0.094 \\
$\mathrm{HgCl}_{2}$ & 0.088 & 0.04 & $4.6 \%$ & 71.216 \\
\hline
\end{tabular}




\subsection{Degradation Assay in Natural Sewage}

For the degradation of dyes in wastewater, a large number of microorganisms have now been screened, with numerous lab studies [52]. However, the composition of natural sewage is very complex [53], so it is necessary to explore whether screened microorganisms perform so well when treating natural wastewater. The typical aniline blue content in natural wastewater is $398.5 \pm 2.85$ $\mathrm{mg} / \mathrm{L} .4 \mathrm{ml}$ of Lysinibacillus fusiformis N019a. $\left(1.5 \times 10^{8} \mathrm{CFU} / \mathrm{mL}\right)$ was inoculated into $100 \mathrm{ml}$ of natural sewage. After $16 \mathrm{~h}, 80.1 \%$ of the aniline blue had been removed (see Figure 5). These results suggest that Lysinibacillus fusiformis N019a performs well in natural wastewater.

\subsection{Phytotoxicity and Microbial Toxicity Assay}

The microbes used for dye degradation/degradation end up being disposed of in the environment and in bodies of water. In that case, it is important to ensure that the end-products of dye degradation/degradation processes are safe for the environment and their toxicity must be assessed [54].

In order to assess the phytotoxicity and microbial toxicity of aniline blue and its degradation/degradation products, the plumule length and germination of tobacco, corn and tomatoes were measured, with MSM being used as a control. The toxicity to Bacillus amyloliquefaciens ZM9 was also assessed and the mean inhibition zone (diameter in $\mathrm{cm}$ ) was recorded after $24 \mathrm{~h}$ of incubation at $30^{\circ} \mathrm{C}$ [44] [46]. The average germination of tobacco treated by MSM, aniline blue and fermentation supernatant was $89 \% \pm 7.37 \%, 43 \% \pm 1.25 \%$, and $77 \% \pm 0.94 \%$, respectively (Figure 6(a)). The length (shoots + roots) of the tobacco treated by MSM, aniline blue and fermentation supernatant was $69.72 \pm 5.91 \mathrm{~mm}, 58.09 \pm$ $6.53 \mathrm{~mm}$, and $62.60 \pm 4.04 \mathrm{~mm}$, respectively (Figure 6(b)). The germination and the length of the shoots and roots show that the degradation product has a low toxicity to plants. The diameter of the inhibition zone for Bacillus amyloliquefaciens ZM9 for MSM, aniline blue and fermentation supernatant was $0 \mathrm{~mm}$,

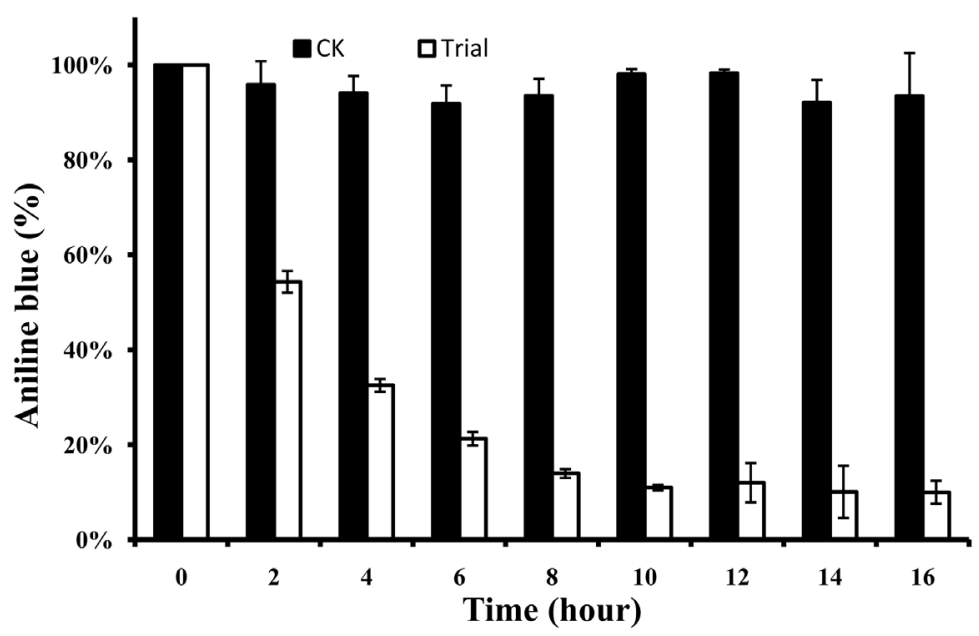

Figure 5. The removal of aniline blue in natural wastewater by lysinibacillus sp. N019a. 


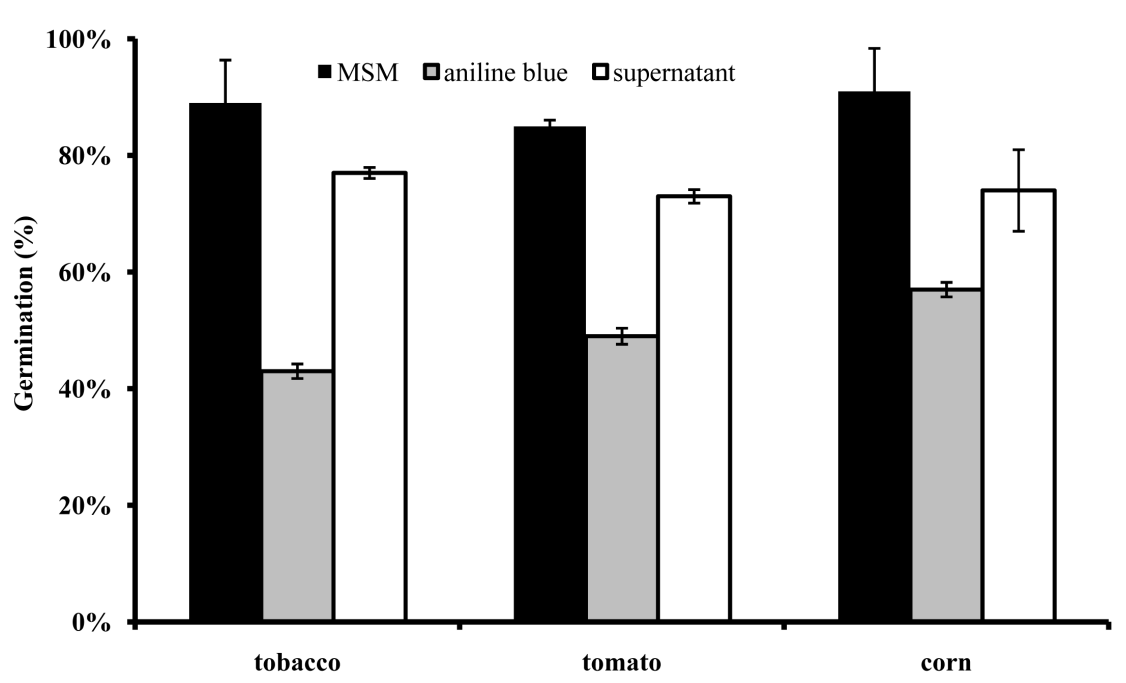

(a)

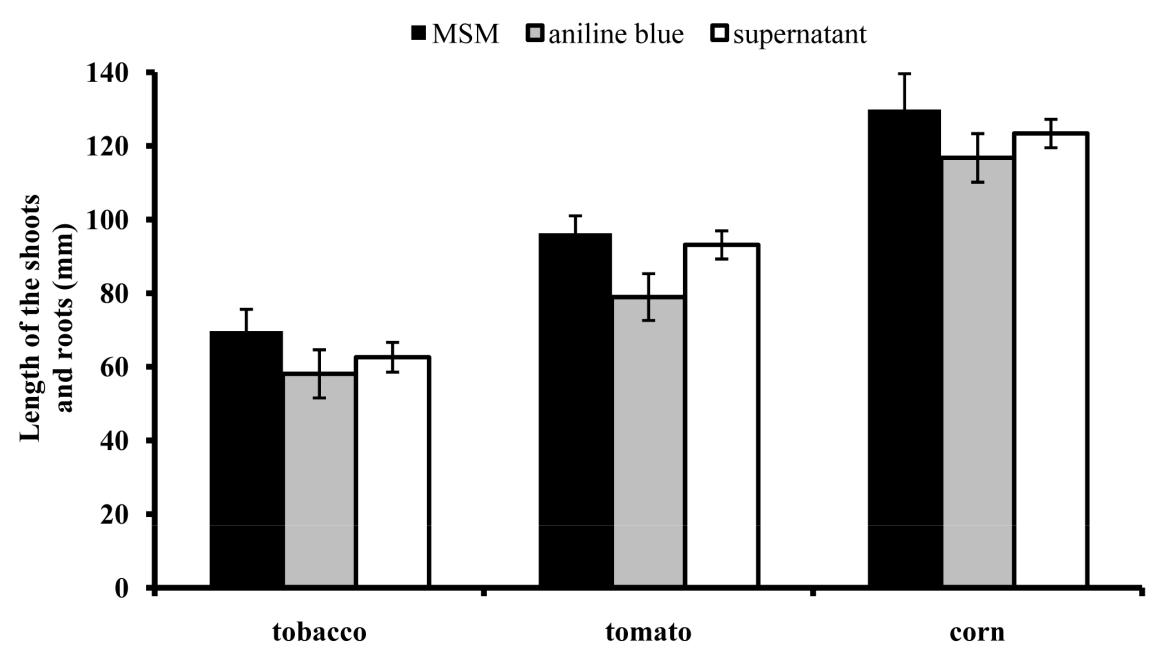

(b)

Figure 6. Phytotoxicity of aniline blue and its degradation products. Germination (a) and the length of the shoots and roots (b) of tobacco, tomatoes and corn were measured.

$8.95 \pm 0.21 \mathrm{~mm}, 2.35 \pm 0.19 \mathrm{~mm}$, respectively. These results once again indicate that the product of aniline blue degradation does not have a particularly toxic nature. Previous investigations have shown that the product of some kinds of triphenylmethane dye degradation by microbes have almost no toxicity at all [44]. However, in this study, there was still less toxicity for the fermentation supernatant. This may imply that some of the aniline blue was not completely degraded. Indeed, our results have shown that $3.3 \%$ of the aniline blue was still not degraded after $24 \mathrm{~h}$ (see Figure 3 ).

\section{Conclusion}

A strain of microorganism, Lysinibacillus fusiformis N019a, was screened from the natural environment and its capacity for aniline blue degradation was analyzed using a UV-visible spectrophotometer. $96.7 \%$ of the aniline blue had been 
degraded after $24 \mathrm{~h}$. The efficiency of aniline blue degradation induced by Lysinibacillus fusiformis $\mathrm{N} 019 \mathrm{a}$ is notably higher than that for some other microbes (see Figures 1-3). On the basis of previous investigations [6] [55], the disappearance of absorption peaks can be taken to demonstrate that the color removal of aniline blue by Lysinibacillus fusiformis N019a was largely attributable to biodegradation. Lysinibacillus fusiformis N019a was also found to effectively degrade aniline blue in natural sewage and it has a strong resistance to the heavy metallic ions $\mathrm{Cu}^{2+}, \mathrm{Mn}^{2+}, \mathrm{Zn}^{2+}$, and $\mathrm{Pb}^{2+}$ (see Figures 4-6 and Table 1). We were further able to confirm that the product of aniline blue degradation by Lysinibacillus fusiformis N019a has a low toxicity to plants and microbes (Figure 6).

\section{Acknowledgements}

This work was supported by the key technology projects of China National Tobacco Corporation (CNTC) under Contract No. 110201502014 and No. 110201502018, and the key technology projects of Hubei tobacco companies under Contract No. 027Y2014-013.

\section{Conflicts of Interest}

The authors declare no conflicts of interest regarding the publication of this paper.

\section{References}

[1] Yamjala, K., Nainar, M.S. and Ramisetti, N.R. (2016) Methods for the Analysis of Azo Dyes Employed in Food Industry-A Review. Food Chemistry, 192, 813-824. https://doi.org/10.1016/j.foodchem.2015.07.085

[2] Alicia, P., Julia, C., María, J.P. and Jose, M.D. (2017) Biological Treatment of Model Dyes and Textile Wastewaters. Chemosphere, 181, 168-177. https://doi.org/10.1016/j.chemosphere.2017.04.046

[3] Daneshvar, N., Ayazloo, M., Khataee, A.R. and Pourhassan, M. (2007) Biological Decolorization of Dye Solution Containing Malachite Green by Microalgae Cosmarium fusiformis. Bioresource Technology, 98, 1176-1182. https://doi.org/10.1016/j.biortech.2006.05.025

[4] Ewa, Z.G., Wioletta, P. and Elżbieta, G.S. (2015) Dye Decolourisation Using Two Klebsiella Strains. Water, Air, \& Soil Pollution, 226, 2249. https://doi.org/10.1007/s11270-014-2249-6

[5] Papadopoulou, E., Vafeiadi, M., Agramunt, S., Basagana, X., et al. (2013) Anogenital Distances in Newborns and Children from Spain and Greece: Predictors, Tracking and Reliability. Paediatric and Perinatal Epidemiology, 27, 89-99. https://doi.org/10.1111/ppe.12022

[6] Lamia, A., Karima, B., Hedi, B.M., Saousen, H., Abdelkrim, C. and Amina, B. (2017) In Vitro Mutagenicity, NMR Metabolite Characterization of Azo and Triphenylmethanes Dyes by Adherents Bacteria and the Role of the "CNA" Adhesion Gene in Activated Sludge. Microbial Pathogenesis, 103, 29-39.

https://doi.org/10.1016/j.micpath.2016.12.016

[7] Chen, S.H. and Ting, A.S.Y. (2015) Biodecolorization and Biodegradation Potential of Recalcitrant Triphenylmethane Dyes by Coriolopsis fusiformis Isolated from 
Compost. Journal of Environmental Management, 150, 274-280.

https://doi.org/10.1016/j.jenvman.2014.09.014

[8] Li, G.H., Peng, L., Ding, Z.Y., Liu, Y.F, Gu, Z.H., Zhang, L. and Shi, G.Y. (2014) Decolorization and Biodegradation of Triphenylmethane Dyes by a Novel Rhodococcus qingshengii JB301 Isolated from Sawdust. Annals of Microbiology, 64, 1575-1586. https://doi.org/10.1007/s13213-014-0801-7

[9] Solís, M., Solís, A., Perez, H.I., Manjarrez, N. and Flores, M. (2012) Microbial Decolouration of Azo Dyes: A Review. Process Biochemistry, 47, 1723-1748. https://doi.org/10.1016/j.procbio.2012.08.014

[10] Nidadavolu, H.B., Gudikandula, K., Pabba, S.K. and Maringant, S.C. (2013) Decolorization of Triphenyl Methane Dyes by Fomitopsis feei. Natural Science, 5, 30-35. https://doi.org/10.4236/ns.2013.56A005

[11] Soloman, P.A., Basha, C.A., Velan, M. and Balasubramanian, N. (2010) Electro Oxidation of Malachite Green and Modeling Using ANN. Chemical and Biochemical Engineering Quarterly, 24, 445-452.

[12] Wu, Y.M., Xiao, X., Xu, C.C., Cao, D.M. and Du, D.L. (2013) Decolorization and Detoxification of a Sulfonated Triphenylmethane Dye Aniline Blue by Shewanella oneidensis MR-1 under Anaerobic Conditions. Applied Microbiology and Biotechnology, 97, 7439-7446. https://doi.org/10.1007/s00253-012-4476-3

[13] Shedbalkar, U., Dhanve, R. and Jadhav, J. (2008) Biodegradation of Triphenylmethane Dye Cotton Blue by Penicillium ochrochloron MTCC 517. Journal of Hazardous Materials, 157, 472-479. https://doi.org/10.1016/j.jhazmat.2008.01.023

[14] Culp, S.J., Mellick, P.W., Trotter, R.W., Greenlees, K.J., Kodell, R.L. and Beland, F.A. (2006) Carcinogenicity of Malachite Green Chloride and Leucomalachite Green in $\mathrm{B} 6 \mathrm{C} 3 \mathrm{~F}(1)$ Mice and F344 Rats. Food and Chemical Toxicology, 44, 1204-1212. https://doi.org/10.1016/j.fct.2006.01.016

[15] Mani, S. and Bharagava, R.N. (2016) Exposure to Crystal Violet, Its Toxic, Genotoxic and Carcinogenic Effects on Environment and Its Degradation and Detoxification for Environmental Safety. Reviews of Environmental Contamination and Toxicology, 237, 71-104. https://doi.org/10.1007/978-3-319-23573-8_4

[16] Ayed, L., Chaieb, K., Cheref, A. and Bakhrouf, A. (2010) Biodegradation and Decolorization of Triphenylmethane Dyes by Staphylococcus epidermidis. Desalination, 260, 137-146. https://doi.org/10.1016/j.desal.2010.04.052

[17] Holkar, C.R., Pandit, A.B. and Pinjari, D.V. (2014) Kinetics of Biological Decolorisation of Anthraquinone Based Reactive Blue 19 Using an Isolated Strain of Enterobacter fusiformis F NCIM 5545. Bioresource Technology, 173, 342-351. https://doi.org/10.1016/j.biortech.2014.09.108

[18] Khataee, A.R., Pons, M.N. and Zahraa, O. (2009) Photocatalytic Degradation of Three Azo Dyes Using Immobilized TiO(2) Nanoparticles on Glass Plates Activated by UV Light Irradiation: Influence of Dye Molecular Structure. Journal of Hazardous Materials, 168, 451-457. https://doi.org/10.1016/j.jhazmat.2009.02.052

[19] Cui, D.Z., Zhang, H., He, R.B. and Zhao, M. (2016) The Comparative Study on the Rapid Decolorization of Azo, Anthraquinone and Triphenylmethane Dyes by Anaerobic Sludge. International Journal of Environmental Research and Public Health, 13, 1053. https://doi.org/10.3390/ijerph13111053

[20] Ma, X.J., Liu, L., Li, Q.Q., Liu, Y.Y., Yi, L., Ma, L.X. and Zhai, C. (2017) High-Level Expression of a Bacterial Laccase, CueO from Escherichia coli $\mathrm{K} 12$ in Pichia pastoris GS115 and Its Application on the Decolorization of Synthetic Dyes. Enzyme and Microbial Technology, 103, 34-41. https://doi.org/10.1016/j.enzmictec.2017.04.004 
[21] Koyani, R.D., Sanghvi, G.V., Sharma, R.K. and Rajput, K.S. (2013) Contribution of Lignin Degrading Enzymes in Decolourisation and Degradation of Reactive Textile Dyes. International Biodeterioration \& Biodegradation, 77, 1-9. https://doi.org/10.1016/j.ibiod.2012.10.006

[22] Younes, S., Bouallagui, Z. and Sayadi, S. (2012) Catalytic Behavior and Detoxifying Ability of an Atypical Homotrimeric Laccase from the Thermophilic Strain Scytalidium thermophilum on Selected Azo and Triarylmethane Dyes. Journal of Molecular Catalysis B: Enzymatic, 79, 41-48. https://doi.org/10.1016/j.molcatb.2012.03.017

[23] Casas, N., Parella, T., Vincent, T., Caminal, G. and Sarra, M. (2009) Metabolites from the Biodegradation of Triphenylmethane Dyes by Trametes versicolor or Laccase. Chemosphere, 75, 1344-1349.

https://doi.org/10.1016/j.chemosphere.2009.02.029

[24] Eichlerová, I., Homolka, L. and Nerud, F. (2006) Synthetic Dye Decolorization Capacity of White Rot Fungus Dichomitus squalens. Bioresource Technology, 97, 2153-2159. https://doi.org/10.1016/j.biortech.2005.09.014

[25] Shedbalkar, U., Dhanve, R. and Jadhav, J. (2008) Biodegradation of Triphenylmethane Dye Cotton Blue by Penicillium ochrochloron MTCC517. Journal of Hazardous Materials, 157, 472-479. https://doi.org/10.1016/j.jhazmat.2008.01.023

[26] Bumpus, J.A. and Brock, B.J. (1988) Biodegradation of Crystal Violet by the White Rot Fungus Phanerochaete chrysosporium. Applied and Environmental Microbiology, 54, 1143-1150.

[27] Novotný, C., Rawal, B., Bhatt, M., Patel, M., Sasek, V. and Molitoris, H.P. (2001) Capacity of Irpex lacteus and Pleurotus ostreatus for Decolorization of Chemically Different Dyes. Journal of Biotechnology, 89, 113-122. https://doi.org/10.1016/S0168-1656(01)00321-2

[28] Saratale, G.D., Kalme, S.D. and Govindwar, S.P. (2006) Decolorisation of Textile Dyes by Aspergillus ochraceus (NCIM-1146). Indian Journal of Biotechnology, 5, 407-410.

[29] Jasinska, A., Zalska, R.O., Bernat, S., Paraszkiewicz, P. and Długo, K. (2012) Malachite Green Decolorization by Non-Basidiomycete Filamentous Fungi of Penicillium pinophilum and Myrothecium roridum. International Biodeterioration \& Biodegradation, 73, 33-40. https://doi.org/10.1016/j.ibiod.2012.06.025

[30] Chmelová, D. and Ondrejovic, M. (2016) Purification and Characterization of Extracellular Laccase Produced by Ceriporiopsis subvermispora and Decolorization of Triphenylmethane Dyes. Journal of Basic Microbiology, 56, 1173-1182. https://doi.org/10.1002/jobm.201600152

[31] Du, L.N., Zhao, M., Li, G., Zhao, X.P. and Zhao, Y.H. (2012) Highly Efficient Decolorization of Malachite Green by a Novel Micrococcus fusiformis Strain BD15. Environmental Science and Pollution Research, 30, 1-10.

[32] Nishiya, Y. and Yamamoto, Y. (2007) Characterization of a NADH: Dichlorophenol Oxidoreductase from Bacillus subtilis. Bioscience, Biotechnology, and Biochemistry, 71, 611-614. https://doi.org/10.1271/bbb.60548

[33] Zhuo, R., Ma, L., Fan, F., Gong, Y., et al. (2011) Decolorization of Different Dyes by a Newly Isolated White-Rot Fungi Strain Ganoderma fusiformis En3 and Cloning and Functional Analysis of Its Laccase Gene. Journal of Hazardous Materials, 192, 855-873. https://doi.org/10.1016/j.jhazmat.2011.05.106

[34] Anastasi, A., Parato, B., Spina, F., Tigini, V., Prigione, V. and Varese, G.C. (2011) Decolorization and Detoxification in the Fungal Treatment of Textile Wastewaters from Dyeing Processes. New Biotechnology, 29, 38-45. 
https://doi.org/10.1016/j.nbt.2011.08.006

[35] Saratale, R.G., Saratale, G.D., Chang, J.S. and Govindwar, S.P. (2010) Decolorization and Biodegradation of Reactive Dyes and Dye Wastewater by a Developed Bacterial Consortium. Biodegradation, 21, 999-1015. https://doi.org/10.1007/s10532-010-9360-1

[36] Cheriaa, J., Khaireddine, M., Rouabhia, M. and Bakhrouf, A. (2012) Removal of Triphenylmethane Dyes by Bacterial Consortium. The Scientific World Journal, 2012, Article ID: 512454.

[37] Kittl, R., Mueangtoom, K., Gonaus, C., Khazaneh, S.T., Sygmund, C., Haltrich, D. and Ludwig, R. (2012) A Chloride Tolerant Laccase from the Plant Pathogen Ascomycete Botrytis aclada Expressed at High Levels in Pichia pastoris. Journal of Biotechnology, 157, 304-314. https://doi.org/10.1016/j.jbiotec.2011.11.021

[38] Kim, J.M., Park, S.M. and Kim, D.H. (2010) Heterologous Expression of a Tannic Acid-Inducible Laccase 3 of Cryphonectria parasitica in Saccharomyces cerevisiae. BMC Biotechnology, 10, 18. https://doi.org/10.1186/1472-6750-10-18

[39] Ma, Y.H., Li, L., Lu, M. and He, J.C. (2016) Isolation of Aniline Blue-Discoloring Actinomyces and Its Decolorization Characteristics. Acta Scientiae Circumstantiae, 36, 4361-4366.

[40] Matsumoto, K., Nacatsu, T. and Kusanagi, T. (1995) Material, Fetal Methemoglobinomia and Fetal Hypoxia in Rats Treated with Aniline Hydrochloride. Teratology, 52, 144-148.

[41] Herburger, K. and Holzinger, A. (2016) Aniline Blue and Calcofluor White Staining of Callose and Cellulose in the Streptophyte Green Algae Zygnema and Klebsormidium. Bio-Protocol, 6, 20. https://doi.org/10.21769/BioProtoc.1969

[42] Yoshida, S., Ohkusu, M., Hata, K., Yarita, K., Fujii, T. and Takeo, K. (2001) Early Death at Medium Acidification and Survival after Low pH Adaptation in Cryptococcus neoformans. Mycoscience, 42, 535-541. https://doi.org/10.1007/BF02460951

[43] Azmi, W., Sanir, K. and Banerjee, U.C. (1998) Biodegradation of Triphenylmethane Dyes. Enzyme and Microbial Technology, 22, 185-191. https://doi.org/10.1016/S0141-0229(97)00159-2

[44] Lamia, A., Kamel, C., Abdelkarim, C. and Amina, B. (2010) Biodegradation and Decolorization of Triphenylmethane Dyes by Staphylococcus epidermidis. Desalination, 260, 137-146. https://doi.org/10.1016/j.desal.2010.04.052

[45] Wu, B., Wang, X., Yang, L., et al. (2016) Effects of Bacillus amyloliquefaciens ZM9 on Bacterial Wilt and Rhizosphere Microbial Communities of Tobacco. Applied Soil Ecology, 103, 1-12. https://doi.org/10.1016/j.apsoil.2016.03.002

[46] Jadhav, U.U., Dawkar, V.V., Ghodake, S.G. and Sanjay, P.G. (2008) Biodegradation of Direct Red 5B, a Textile Dye by Newly Isolated Comamonas fusiformis UVS. Journal of Hazardous Materials, 158, 507-516. https://doi.org/10.1016/j.jhazmat.2008.01.099

[47] Chen, L., Lin, Y.H., He, X.B., Tan, L., Tang, X. and Hu, Y.T. (2011) Optimization of Decolorization of Aniline Blue Dye by White-Rot Fungus Bjerkandera fumosa X. Hubei Agricultural Sciences, 50, 4178-4184.

[48] Lin, Y.H., Chen, L., He, X.B., He, Y.Q. and Zhou, X. (2010) Biodegradation of Aniline Blue Dye by a Fungus Mucoromycotina fusiformis HS-3. Microbiology China, 37, 1727-1733.

[49] Chen, X.C., Pan, H.H., Wu, Y.M., Yu, H.D., Lu, J. and Li, Y.(2015) Treatment of Aniline Compounds in Dyeing Wastewater by Fenton-Coagulation Method, 38, 
144-147.

[50] Chen, C.H., Chang, C.F. and Liu, S.M. (2010) Partial Degradation Mechanisms of Malachite Green and Methyl Violet B by Shewanella decolorationis NTOU1 under Anaerobic Conditions. Journal of Hazardous Materials, 177, 281-289.

https://doi.org/10.1016/j.jhazmat.2009.12.030

[51] Zhang, J., Tan, Y., Jiang, Y.C., Hu, M.C., Li, S.N. and Zhai, Q.G. (2014) Rapid Decolorization of Anthraquinone and Triphenylmethane Dye Using Chloroperoxidase: Catalytic Mechanism, Analysis of Products and Degradation Route. Journal of Chemical Engineering, 244, 9-18. https://doi.org/10.1016/j.cej.2014.01.063

[52] Mishra, S. and Maiti, A. (2018) The Efficacy of Bacterial Species to Decolourise Reactive Azo, Anthroquinone and Triphenylmethane Dyes from Wastewater: A Review. Environmental Science and Pollution Research, 25, 8286-8314. https://doi.org/10.1007/s11356-018-1273-2

[53] Zhang, X., Wu, Y., Xiao, G., Tang, Z., Wang, M., et al. (2017) Simultaneous Photocatalytic and Microbial Degradation of Dye-Containing Wastewater by a Novel g-C3N4-P25/Photosynthetic Bacteria Composite. PLoS ONE, 12, e0172747. https://doi.org/10.1371/journal.pone.0172747

[54] Chaudhari, A.U., Paul, D., Dhotre, D. and Kodam, K.M. (2017) Effective Biotrans-Formation and Detoxification of Anthraquinone Dye Reactive Blue 4 by Using Aerobic Bacterial Granules. Water Research, 12, 603-613. https://doi.org/10.1016/j.watres.2017.06.005

[55] Chang, J.S. and Kuo, T.S. (2000) Kinetics of Bacterial Decolorization of Azo Dye with Escherichia coli $\mathrm{NO}_{3}$. Bioresource Technology, 75, 107-111. https://doi.org/10.1016/S0960-8524(00)00049-3 